\title{
Appendiceal adenocarcinoma masquerading as a primary rectal tumour
}

Tamara M Vu, MBBS

Jonathan Alastair Simpson, BMBS, PhD, FRCS

A Craig Lynch, MBChB, MMedSci, FRACS

Satish Warrier, MBBS, MS, FRACS

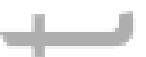

Alexander Heriot, MBBChir, FRCS (Gen.)

Department of Surgical Oncology, Peter MacCallum Cancer Centre, East Melbourne, Victoria, Australia

Figures: 3

Word count: 667

Corresponding author:

Tamara $\mathrm{M} \mathrm{Vu}$

tamara.vu@petermac.org

0395651111

Department of Surgical Oncology

Peter MacCallum Cancer Centre

St Andrew's Place

East Melbourne Victoria 3002
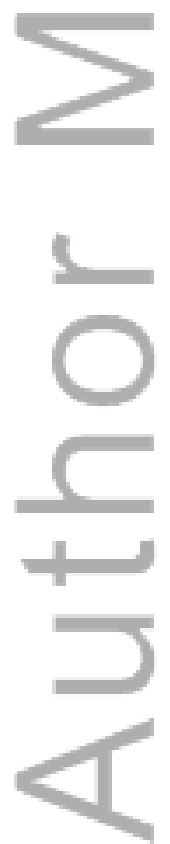

This is the author manuscript accepted for publication and has undergone full peer review but has not been through the copyediting, typesetting, pagination and proofreading process, which may lead to differences between this version and the Version of Record. Please cite this article as doi: 10.1111/ans.13485

This article is protected by copyright. All rights reserved. 
Appendiceal adenocarcinoma is a rare gastrointestinal lesion that is rarely invasive of pelvic structures at diagnosis. We present an unusual case of one such lesion that invaded the rectum, which was detected on endoscopy performed for investigation of haematochezia. Involvement of a multidisciplinary team and extensive en bloc resection was able to achieve a curative outcome in this case. A previously well 59-year-old man presented with a large bleed per rectum. Colonoscopy demonstrated a mid rectal tumour, $10 \mathrm{~cm}$ from the anal verge. Histology confirmed a moderately differentiated adenocarcinoma. Staging CT highlighted a hyperdense structure extending from the caecal pole into the right pelvis and invading the wall of the rectum, in keeping with a primary appendiceal malignancy.

Staging MRI revealed a high signal upper rectal mass with a craniocaudal height of $42 \mathrm{~mm}$ that extended into the mesorectal fascia on the right and into the base of the caecum contiguous with the appendix. The tumour invaded the peritoneal reflection adjacent to the iliac arteries and involved the right ureter without obvious bladder invasion. Staging PET scan showed a solitary pelvic mass with no nodal enlargement, peritoneal disease or distant metastases. The patient was discussed at the Lower GI surgical oncology MDT where there was agreement that this was a primary appendiceal malignancy with local invasion and should be managed in line with current guidelines for advanced pelvic malignancy. He proceeded to neoadjuvant long course chemoradiotherapy with 5-fluorouracil and 50.4Gy for five weeks. Restaging imaging demonstrated an interval reduction in size of the known invasive appendiceal cancer. This was followed by definitive surgical resection.

This article is protected by copyright. All rights reserved. 
At surgery, ureteric stenting was performed to assist in delineating the plane between the tumour and retroperitoneal structures. The mass was found to arise in the appendix and adhere to the right ureter at the level of the vesicoureteric junction before invading the rectum. En bloc low anterior resection and right hemicolectomy was performed in combination with a partial cystectomy and distal ureterectomy. The ureter was reimplanted in the dome of the bladder. The patient was defunctioned with a covering loop ileostomy. Histopathology demonstrated a pT4bN0 perforated moderately differentiated mucinous adenocarcinoma arising in the distal appendix and directly extending into the rectum. Tumour involved perivesical and periureteric fat but did not invade the right ureter. Postoperative recovery was complicated by a small rectocolic anastamotic leak that resolved with conservative management. The patient was discharged home on day 21 without further complications. He proceeded to further postoperative chemotherapy. His stoma was reversed 17 months following his operation. He is well and recurrence free 18 months later.

Appendiceal adenocarcinoma is a rare gastrointestinal cancer with a reported incidence of $0.2 / 100000,{ }^{1}$ although it is the commonest appendiceal malignancy. ${ }^{2}$ It most commonly presents as an incidental finding at appendicectomy performed for acute appendicitis, although a minority of cases present as a pelvic mass. ${ }^{3}$ Such masses can rarely be locally invasive into adjacent pelvic structures, typically the bladder. ${ }^{4}{ }^{6}$ In the setting of bladder invasion, formation of vesicoappendiceal fistulae has been reported. ${ }^{7} 8$ There is a much smaller literature describing primary appendiceal adenocarcinoma invasive to the rectum at diagnosis, with only one previous reported case. ${ }^{9}$ Recommendations regarding management of appendiceal 
adenocarcinoma focus primarily on disease confined to the appendix (T3 or less). The management of this type of early appendiceal adenocarcinoma with right hemicolectomy is essentially uncontroversial. ${ }^{10}$ However, there is paucity of formal guidelines for the management of advanced appendiceal malignancy. The experience of our centre is that this type of advanced complex tumours should be managed in the same manner as other advanced pelvic malignancies. In this case the management plan was formulated in a MDT and the decision to treat with neoadjuvant chemoradiotherapy resulted in a reduction in tumour bulk. A colorectal surgeon and urologist carried out a radical resection to achieve R0 margins. The ongoing follow-up of this patient in a dedicated Lower GI surgical oncology outpatient unit according to the standard colorectal carcinoma surveillance regime will maximise the likelihood that any recurrent disease is detected and managed promptly. ${ }^{11}$

\footnotetext{
${ }^{1}$ Bosman FT, Carneiro F, Hruban RH, Theise ND. WHO Classification of Tumours of the Digestive System, $4^{\text {th }}$ edn. Geneva: IARC, 2010.

${ }^{2}$ Benedix F, Reimer A, Gastinger I et al. Primary appendiceal carcinoma - epidemiology, surgery and survival: results of a German multi-center study. Eur J Surg Oncol. 2010: 36(8): 763-71.

${ }^{3}$ Nitecki SS, Wolff BG, Schlinkert R, Sarr MG. The natural history of surgically treated primary adenocarcinoma of the appendix. Ann Surg. 1994: 219(1): 51-7.

${ }^{4}$ Henry R, Bracken RB, Ayala A. Appendiceal carcinoma mimicking primary bladder cancer. $J$ Urol. 1980: 123(4): 590-1.

${ }^{5}$ Deng K, Zhang CQ, Wang GL, Li W. Primary appendiceal mucinous adenocarcinoma mimicking bladder carcinoma: A case report and review of the literature. Oncol Lett. 2014: 7(4): 1270-2.

${ }^{6} \mathrm{Qu}$ R, Jiang Y, Chen S, Dong Q. Primary appendiceal adenocarcinoma masquerading as primary bladder tumour: a case report and review of literatures. Indian J Surg. 2015: 77(Suppl 1): 16-8.

${ }^{7}$ Ikeda I, Miura T, Kondo I. Case of vesico appendiceal fistula secondary to mucinous adenocarcinoma of the appendix. The Journal of Urology. 1995: 153: 1220-1.

${ }^{8}$ Orso IRB, Ambar Pinto R, Ramos MFKP et al. Vesico-appendiceal fistula in a mucinous adenocarcinoma of the appendix. Arq Bras Cir Dig. 2008: 21(1).

${ }^{9}$ Keating JP, Mouat C, Strettell MD. Appendiceal carcinoma masquerading as a rectal villous adenoma. Gastrointest Endosc. 2001: 53(1): 124-5.

${ }^{10}$ Benedix F, Reimer A, Gastinger I et al. Primary appendiceal carcinoma - epidemiology, surgery and survival: results of a German multi-center study. Eur J Surg Oncol. 2010: 36(8): 763-71.

${ }^{11}$ Primrose JN, Perera R, Gray A et al. Effect of 3 to 5 years of scheduled CEA and CT follow-up to detect recurrence of colorectal cancer: The FACS randomized clinical trial. JAMA. 2014 : 311(3): $263-$ 70 .
} 


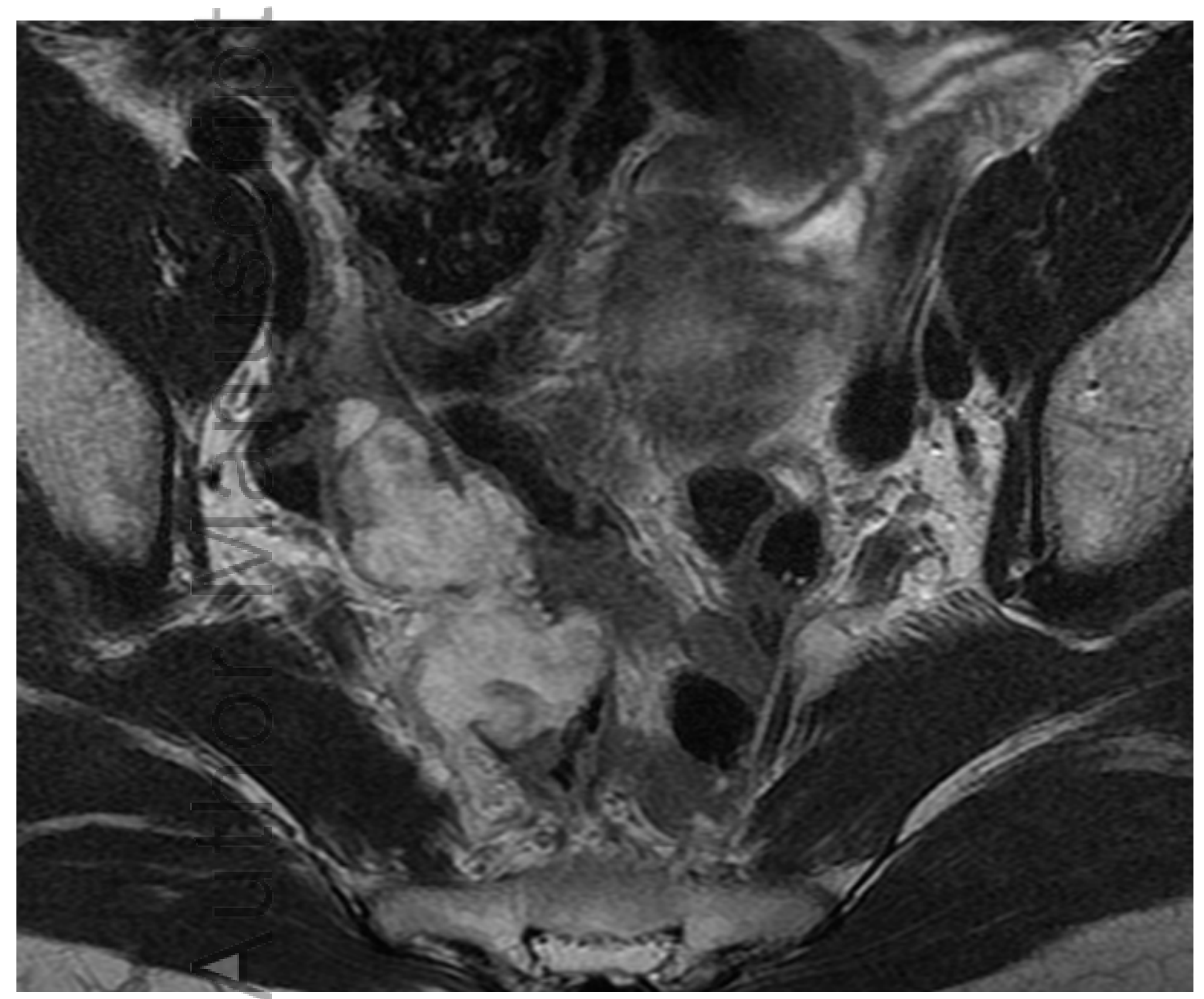

Figure 1.TIF

This article is protected by copyright. All rights reserved. 


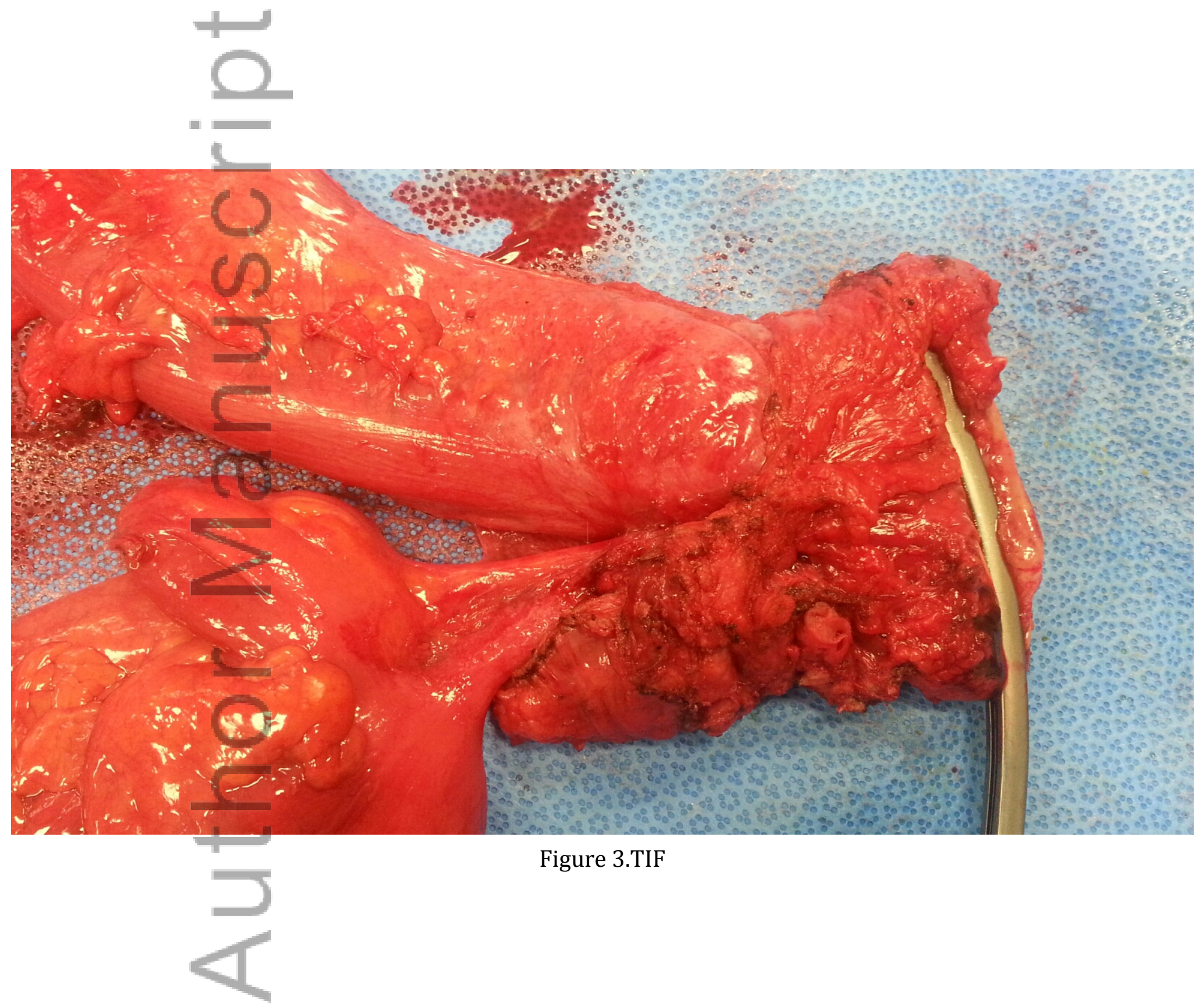

This article is protected by copyright. All rights reserved. 


\section{University Library}

\section{- M M I N E R VA A gateway to Melbourne's research publications}

Minerva Access is the Institutional Repository of The University of Melbourne

Author/s:

Vu, TM;Simpson, JA;Lynch, AC;Warrier, S; Heriot, A

Title:

Appendiceal adenocarcinoma masquerading as a primary rectal tumour

Date:

2018-06-01

Citation:

Vu, T. M., Simpson, J. A., Lynch, A. C., Warrier, S. \& Heriot, A. (2018). Appendiceal adenocarcinoma masquerading as a primary rectal tumour. ANZ JOURNAL OF SURGERY, 88 (6), pp.E556-E557. https://doi.org/10.1111/ans.13485.

Persistent Link:

http://hdl.handle.net/11343/292236 